\title{
Agricultural-to-hydropower water transfers: sharing water and benefits in hydropower-irrigation systems
}

\author{
A. Tilmant ${ }^{1}$, Q. Goor ${ }^{2}$, and D. Pinte ${ }^{2}$ \\ ${ }^{1}$ UNESCO-IHE, Department of Management and Institution, Delft, The Netherlands \\ ${ }^{2}$ Université catholique de Louvain, Department of Environmental Sciences, Belgium
}

Received: 5 February 2009 - Published in Hydrol. Earth Syst. Sci. Discuss.: 9 March 2009

Revised: 27 May 2009 - Accepted: 4 June 2009 - Published: 9 July 2009

\begin{abstract}
This paper presents a methodology to assess agricultural-to-hydropower water transfers in water resources systems where irrigation crop production and hydropower generation are the main economic activities. In many countries, water for crop irrigation is often considered as a static asset: irrigation water is usually allocated by a system of limited annual rights to use a prescribed volume of water, which remains to a large extent independent of the availability of water in the basin. The opportunity cost (forgone benefits) of this static management approach may be important in river basins where large irrigation areas are present in the upstream reaches. Continuously adjusting allocation decisions based on the hydrologic status of the system will lead to the temporary reallocation of some (or all) of the irrigation water downstream to consumptive and/or nonconsumptive users. Such a dynamic allocation process will increase the social benefits if the sum of the downstream productivities exceeds those of the upstream farmers whose entitlements are curtailed. However, this process will be socially acceptable if upstream farmers are compensated for increasing the availability of water downstream. This paper also presents a methodology to derive the individual contribution of downstream non-consumptive users, i.e. hydropower plants, to the financial compensation of upstream farmers. This dynamic management approach is illustrated with a cascade of multipurpose reservoirs in the Euphrates river basin. The analysis of simulation results reveals that, on average, the annual benefits obtained with the dynamic allocation process are $6 \%$ higher that those derived from a static allocation.
\end{abstract}

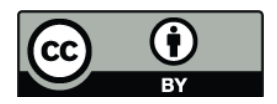

Correspondence to: A. Tilmant (a.tilmant@unesco-ihe.org)

\section{Introduction}

As the competition for water is likely to increase in the near future due to socioeconomic development and population growth, water resources managers will face hard choices when allocating water between competing users. Because water is a vital resource used in multiple sectors, including the environment, the allocation is inherently a political and social process, which is likely to become increasingly scrutinized as the competition grows between the different sectors. Since markets are usually absent or ineffective, the allocation of water between competing demands is achieved administratively taking into account key, often conflicting, objectives such as economic efficiency, equity and maintaining the ecological integrity. Various allocation mechanisms have been developed in order to reconcile the efficiency and equity principles (Dinar et al., 1997; Molle et al., 2007). Another difficulty associated with water resources management comes from the fact that many water using activities generate externalities downstream. Since water flows downstream together with the externalities the natural spatial scale at which water allocation decisions can be made is the river basin. Policy instruments designed to achieve a certain level of economic efficiency and equity should therefore best be developed and implemented at that scale (Davis, 2007).

When crop irrigation is involved, water is usually allocated by a system of annual rights to use a fixed, static volume of water, which is typically less than what farmers would expect (Young, 2005). Farmers' demand for water is derived from the value of its use in crop production, which in turn depends on crop water requirements and crop prices. In the residual method, which is one of the most common valuation methods used in irrigated agriculture, one usually assumes constant crop water requirements (Ward and Michelsen, 2002; Gibbons, 1986). The South-eastern Anatolia Project in Turkey, for example, was planned with a

Published by Copernicus Publications on behalf of the European Geosciences Union. 
fixed irrigation water demand of about $10000 \mathrm{~m}^{3} / \mathrm{ha} / \mathrm{yr}$ (Kolars and Mitchell, 1994; Beaumont, 1996). In the Maule river basin in Chile, because non-consumptive water rights held by power companies cannot negatively affect prior consumptive water rights enjoyed by farmers, hydropower companies are bound to respect pre-defined monthly release targets reflecting agricultural demands (Tilmant et al., 2007). Considering constant irrigation water demands is also a common assumption in multiobjective optimization models for reservoir operation (Labadie, 2004; Yeh, 1985). In the constraint method, for example, the irrigation objective is removed from the objective function and irrigation withdrawals are rather considered as additional constraints to reflect the priority given to the agricultural sector and the (nearly) constant water demands. Oven-Thompson et al. (1982) determine the tradeoff relationship between irrigation and hydropower generation for the High-Aswan dam using the constraint method. The same multiobjective method is used in Tilmant and Kelman (2007) to assess the hydrological risk in the multireservoir system of the Euphrates river basin. In ReVelle (1999), irrigation withdrawals are chosen so as to minimize the deviation from predefined target demands. When crop-water production functions are available, they can be included in the analysis using integrated hydrologic-economic models (Ward et al., 2006; Cai et al., 2003; Rosegrant et al., 2000; Booker and Young, 1994). In Vedula and Kumar (1996), the steady-state operating rules of an irrigation reservoir are derived from a hybrid linear programming-stochastic dynamic programming (LP-SDP) model that takes into account the additive form of the crop yield response function. In this paper we will consider that water demands from the agricultural sector are driven by crop water requirements and that water is administratively allocated using either fixed (static) or variable (dynamic) entitlements.

Moving from a static to a dynamic allocation process in a fully-allocated basin implies that the policies are regularly updated according to the hydrologic status of the river basin. It also contributes to the development of river basin management strategies that increase the productivity of water. Dynamic management approaches are commonly used in the hydropower sector, both in regulated and deregulated electricity markets. In regulated electricity markets, an Independent System Operator (ISO) produces a dispatch based on a least-cost criterion (also called "merit-order" operation): hydropower plants are dispatched so as to minimize the expected operating costs of the hydrothermal electrical system over a given planning period (e.g. 5 years). This exercise is regularly updated according to the status of the system which includes the storage levels in the reservoirs and the latest hydrologic information (Pereira, 1989). In deregulated electricity markets, hydropower companies dynamically manage their assets, which now also include a portfolio of contracts, by generating energy, selling/purchasing energy on the spot market, and selling/purchasing contracts (Scott and Read, 1996; Fleten, 2000; Barosso et al., 2002).
Again, these decisions are regularly updated as hydrologic conditions, spot prices and financial position change. In a multipurpose multireservoir system, continuously adjusting release and withdrawal decisions based on the latest hydrologic information will increase the benefits derived from the system. However, the extent to which such an adjustment can be achieved results from complex spatial and temporal interactions between the physical characteristics of the water resources system (storage, natural flows), the economic and social consequences of rationing and the impacts on natural ecosystems.

As mentioned earlier, a dynamic management approach increases the productivity of water by continuously adjusting allocation decisions based on the status of the water resources system. In other words, such an approach should lead to economic efficient allocation decisions. However, economic efficiency is not the only objective when allocating water between competing users, and must often be tradedoff against equity considerations. Equity objectives are concerned with fairness or justice and tend to redistribute the resources itself or the benefits associated with the use of the resource. When dealing with water resources allocation problems, the equity objectives can take various forms including basic water services or minimum physical allocation. Such egalitarian policies are often criticized by neoclassical economists on the grounds that they entail efficiency losses. To operationalize the notion of equity, egalitarian societies tend to equalize income or welfare by making those who are currently poor better off without significant cost to those who are not poor. In a river basin, operationalizing the notion of equity implies that the redistribution of benefits comes down to sharing the benefits rather the water itself (Sadoff and Grey, 2002; Fisher et al., 2005). In practice, however, redistributing benefits may become a difficult task when water users are distributed along a river and when their uses generate externalities downstream. Irrigation, for example, reduces the availability of water downstream by decreasing the volume of water flowing in the river and degrading the quality of water through polluted return flows. A storage hydroelectric power plant can generate downstream benefits by reducing the impact of flooding, increasing groundwater recharge and maintaining base flows, etc. But at the same time, it can also generate negative externalities on downstream ecosystems by, for example, trapping sediments and altering the natural hydrological regime of the river. Braden and Johnston (2004) and Johnston et al. (2006), for example, evaluate the downstream economic benefits associated with improved storm water management strategies. The benefits from shifting water from the agricultural to the municipal and industrial sectors in the Maipo river basin are analyzed using an integrated hydrologic-economic model in Rosegrant et al. (2000). The opportunity cost of irrigation developments in the upper reaches of the Euphrates-Tigris river basin is assessed through scenario analysis in Tilmant and Kelman (2007). 
In the above examples, the difficulty to allocate water between a downstream and an upstream users is that the former relies on the latter through a natural phenomenon, namely the hydrological cycle. Because water flows from upstream to downstream, an upstream water user is likely to impact, whether positively and/or negatively, his downstream neighbor. This asymmetrical relationship implies that

- if an equitable sharing of water is to be achieved, the upstream user will have to forgo some of his potential benefits;

- if an (economic) efficient sharing of water is to be achieved, an upstream water user will have to pay or to receive from the downstream user compensation for the negative or positive externalities the upstream user generates downstream (Nkomo and van der Zaag, 2004).

In a cascade of reservoirs with both consumptive and nonconsumptive users, the economically efficient allocation decision will depend on the difference between the productivity of the local consumptive user and the sum of the productivities of downstream non-consumptive users. In other words, at a given site in a hydropower-irrigation system, the decision to release water downstream or withdraw it will be based on the comparison of the aggregated productivity of the farmers at that site and the sum of productivities of all hydropower plants located downstream of that site. Consequently, everything else being equal, upstream farmers are likely to be affected by a dynamic allocation process. As mentioned earlier, a proper compensation scheme must therefore be established which can consider the individual losses and benefits. A cascade of hydropower-irrigation reservoir in the Euphrates will be used for illustrative purposes.

\section{Material and methods}

\subsection{Sharing water and benefits: a two-step approach}

The proposed framework for sharing water resources and their benefits in a hydropower-irrigation system relies on a two-step procedure. Economically efficient allocations policies are first identified with the help of an optimization model that seeks to maximize basin-wide net benefits. Then, the financial compensations are calculated from the optimal allocation decisions and marginal water values, which are both available at the optimal solution of the allocation model.

When formulating the water resources allocation problem as an optimization problem, we make the assumption that the river basin is managed by a single institution, an imaginary river basin authority, that maximizes the economic net benefits generated in the basin. With the static allocation scheme, irrigation withdrawals are essentially independent of the status of the water resources system, i.e. the storage levels in the reservoirs and the inflows. In other words, irrigation water rights are met as long as there is enough water in the system. In that case the allocation problem reduces to scheduling releases from the hydropower stations. In the dynamic allocation scheme, both irrigation withdrawals and hydropower releases are key decisions variables that are now directly influenced by the status of the system, and that will be selected so as to maximize basin-wide net benefits. Since the extent and timing of agricultural-to-hydropower water transfers are expected to vary with the availability of water in the basin, a stochastic hydro-economic optimization model, called Stochastic Dual Dynamic Programming (SDDP), will be implemented.

Dynamically managing a water resources system implies that the users at the margin, i.e. the users that are likely to be rationed, must be compensated by those who benefit from the dynamic allocation. If a financial compensation were to be implemented, the compensation should be at least equal to the forgone benefits of those users at the margin. In a hydropower-irrigation system where several consumptive and non-consumptive users are competing for water, upstream consumptive users are likely to be the first to see their entitlements curtailed since they compete with downstream users who can form a coalition to increase their productivity, which will lead to a reallocation downstream. Since several downstream users may benefit from the reallocation of upstream water, we need a mechanism to assess the individual contribution of each beneficiary to the financial compensation of the affected upstream user. As we will see later, the individual contribution of the beneficiary user should be proportional to its productivity.

\subsection{Stochastic dual dynamic programming}

As mentioned earlier, two SDDP formulations will be used to derive the allocation decisions and the relevant economic information. The first formulation seeks to maximize the net benefits from hydropower generation by considering fixed allotments to the irrigation sector as in a static allocation process. The second formulation seeks to maximize the aggregated net benefits from both the irrigation and hydropower sectors by identifying optimal release $r_{t}(j)$ and withdrawal $i_{t}(j)$ decisions at each site $j$ and for each time $t \in[1 \ldots T]$ where $T$ is the length of the planning period. This second formulation corresponds to a dynamic management approach.

SDDP extends the traditional discrete stochastic dynamic programming (SDP) to handle a large state space, i.e. a large number of reservoirs and allocation decisions. In SDP, allocation decisions are made to maximize current benefits plus the expected benefits from future operation, which are represented by the recursively calculated benefit-to-go function $F_{t+1}$ (Tejada-Guibert et al., 1993) . In SDDP, this benefitto-go function is approximated by a piecewise linear function through sampling and decomposition; for each sampled values of the state variables a hyperplane (cut) is constructed and provides an outer approximation of the benefitto-go function. Intuitively, the computational effort should 
be reduced since the value of $F_{t+1}$ can now be derived by extrapolation instead of interpolation as in SDP.

Let $s_{t}$ be the vector of storage volumes at the beginning of time period $t ; r_{t}$ be the vector of releases at the beginning of time period $t ; q_{t}$ be the vector of natural inflows during period $t ; p_{t}$ be the vector of spills; $I_{t}$ be the vector of irrigation withdrawals; $C_{R}$ be the system connectivity matrix $\left(C_{R}(j, k)=1(-1)\right.$ when reservoir $j$ receives(releases) water from(to) reservoir $k$ ); $C_{I}$ is the connectivity matrix of the irrigation system, i.e. $C_{I}(j, d)=\alpha$ when reservoir $j$ receives return flows from the irrigation site $d$ and/or $C_{I}(j, d)=-1$ when water is diverted from reservoir $j$ to the irrigation site $d ; e_{t}$ be the vector of evaporation losses; $\underline{s}$ and $\bar{s}$ are vectors with the minimum and maximum storage volumes respectively; $r$ and $\bar{r}$ are vectors with the minimum and maximum releases respectively; $\pi^{h}$ is the vector of energy prices (\$/MWh); $\theta^{h}$ is the vector of variable costs for hydropower generation(\$/MWh); $c^{h}$ is the vector of production coefficient $\left(\mathrm{MW} / \mathrm{m}^{3} \mathrm{~s}^{-1}\right) ; \tau$ is the number of hours in period $t$.

With the above definitions and using $L$ hyperplanes to approximate $F_{t+1}$, the one-stage optimization problem becomes

$$
F_{t}\left(s_{t}, q_{t-1}\right)=\max \left\{f_{t}\left(s_{t}, q_{t}, r_{t}\right)+F_{t+1}\right\}
$$

subject to

$s_{t+1}-C_{R}\left(r_{t}+p_{t}\right)=s_{t}+q_{t}-e_{t}\left(s_{t}\right)+C_{I}\left(I_{t}\right)$

$\underline{s}_{t+1} \leq s_{t+1} \leq \bar{s}_{t+1}$

$\underline{r}_{t} \leq r_{t} \leq \bar{r}_{t}$

$f_{t}\left(s_{t}, q_{t}, r_{t}\right)=\tau_{t} \sum_{j}\left(\pi_{t}^{h}(j)-\theta^{h}(j)\right) c^{h}(j) r_{t}(j)-\xi_{t} x_{t}$

$$
\left\{\begin{array}{l}
F_{t+1}-\varphi_{t+1}^{1} s_{t+1} \leq \gamma_{t+1}^{1} q_{t}+\beta_{t+1}^{1} \\
\vdots \\
F_{t+1}-\varphi_{t+1}^{L} s_{t+1} \leq \gamma_{t+1}^{L} q_{t}+\beta_{t+1}^{L}
\end{array}\right.
$$

Details on the determination of hyperplanes coefficients $\beta, \varphi$ and $\gamma$ can be found in Tilmant and Kelman (2007). The set of results available at the optimal solution includes the optimal allocation policies at each stage $t$, i.e the vectors $r_{t}$ and $p_{t}$, and the marginal water values $\lambda_{w, t}$, i.e. the Lagrange multipliers associated with the mass balance Eq. (2).

To incorporate irrigation net benefits into the objective function of SDDP, we need a new state variable that would indicate the status of the irrigation sector at any point in space and time. As explained in Tilmant et al. (2008), the new state variable, denoted $y_{t}$, represents the total volume of water allocated to the crops from the beginning of the irrigation until current stage $t$. It is equivalent to a reservoir that would refill during the irrigation season with the irrigation withdrawals $i_{t}$, which are now decision variables, and that would be depleted when crops are harvested and sold. For notational simplicity, we assume one irrigation demand site per abstraction point, but the model can handle as many "irrigation reservoirs" as the number of crops. The immediate benefit function $f_{t}$ at stage $t$ can now include up to three terms: (i) net benefits from hydropower generation, (ii) penalties for violating operating constraints and (iii) net benefits from irrigation. While the first two terms can be observed all year long, the third one can only be observed at the end of the growing season, when agricultural products are harvested and sold. Let $t_{i}$ and $t_{f}$ be the first and last stages of the irrigation season respectively and $\epsilon$ be the vector of irrigation efficiencies. When $t \neq t_{f}$, the immediate benefit function is simply (5), whereas when $t=t_{f}$, that function becomes

$$
\begin{aligned}
f_{t}\left(s_{t}, q_{t}, r_{t}, y_{t}\right) & =\tau_{t} \sum_{j}\left(\pi_{t}^{h}(j)-\theta_{t}^{h}(j)\right) c^{h}(j) r_{t}(j) \\
& -\xi_{t} x_{t} \\
& +\sum_{d} \hat{g}^{d}\left(y_{t}^{d}\right)
\end{aligned}
$$

where $\hat{g}^{d}$ is the net benefit function at the irrigation demand site $d$.

With the above immediate benefit function, the one stage SDDP optimization problem corresponding to the second (dynamic) formulation can be written as

$F_{t}\left(s_{t}, q_{t-1}, y_{t}\right)=\max \left\{f_{t}\left(s_{t}, q_{t}, r_{t}, y_{t}\right)+F_{t+1}\right\}$

subject to

$s_{t+1}-C_{R}\left(r_{t}+p_{t}\right)-C_{I}\left(i_{t}\right)=s_{t}+q_{t}-e_{t}\left(s_{t}\right)$

$y_{t+1}-\epsilon i_{t}=y_{t}$

State and decisions variables have lower and upper bounds:

$\underline{s}_{t+1} \leq s_{t+1} \leq \bar{s}_{t+1}$

$\underline{r}_{t} \leq r_{t} \leq \bar{r}_{t}$

$\underline{i}_{t} \leq i_{t} \leq I_{t}$ 
$\underline{y}_{t+1} \leq y_{t+1} \leq \bar{y}_{t+1}$

Assuming there are $L$ hyperplanes used to approximate $F_{t+1}$, the remaining constraints are:

$\left\{\begin{array}{l}F_{t+1}-\varphi_{t+1}^{1} s_{t+1}-\eta_{t+1}^{1} y_{t+1} \leq \gamma_{t+1}^{1} q_{t}+\beta_{t+1}^{1} \\ \vdots \\ F_{t+1}-\varphi_{t+1}^{L} s_{t+1}-\eta_{t+1}^{L} y_{t+1} \leq \gamma_{t+1}^{L} q_{t}+\beta_{t+1}^{L}\end{array}\right.$

where $\eta_{t+1}$ is a vector of slopes with respect to the new state variable $y_{t+1}$. As explained in Tilmant et al. (2008), $\eta_{t+1}$ is also derived at stage $t+1$ from the Lagrange multipliers $\lambda_{y, t+1}$ associated with the constraints (10).

\subsection{Financial compensation}

Dynamically managing water resources in a river basin consists in continuously adjusting allocation decisions based on the status of the system, which is represented here by the inflows and the storage levels in the reservoirs. For example, under dry conditions, marginal water values will increase therefore signaling that priority be given to most productive uses. However, to make those efficient allocation decisions socially acceptable, a compensation mechanism must be developed in order to compensate the water users who have to forgo some (or all) of their individual benefits so that social benefits are maximized. Here, the compensation mechanism will take the form of a financial transaction from the downstream user who benefit from the water transfer to the upstream user who has to give up some (or all) of his water.

To assess the financial transactions we need the marginal water values at all sites $j$ and for each time period $t$. In the absence of a water market, the value of water is represented by accounting or shadow prices, which can be obtained using mathematical programming as a deductive method (Young, 2005). As mentioned earlier, the marginal water values $\lambda_{w}$ are available at the optimal solution of the SDDP algorithm; they correspond to the Lagrange multipliers (shadow prices) associated with the mass balance Eq. (9). They give the change in the total net benefits due to the availability of an additional unit of water at any site.

Let $I_{t}(j)$ be the monthly prescribed volume of water to be diverted from reservoir $j$ to the irrigation district $j$. Taking into account the efficiency $\epsilon(j)$ of the irrigation system, the crop water requirements correspond to $I_{t}(j) \epsilon(j)$. Without rationing, the sum of the gross monthly water allocations should equal the prescribed annual entitlement, i.e. $\sum_{t=t_{i}}^{t_{f}} i_{t}(j)=I(j)$. As pictured on Fig. 1, we will assume that there is one hydropower plant and one irrigation district per site. Finally, we must also make the distinction between at-source $\left(\lambda_{w}\right)$ and at-site $\left(\lambda_{w}^{*}\right)$ water value: the former is observed at a location where bulk water is diverted, whereas the latter corresponds to the value of water delivered to the farmers, i.e at the end of the conveyance and distribution system.

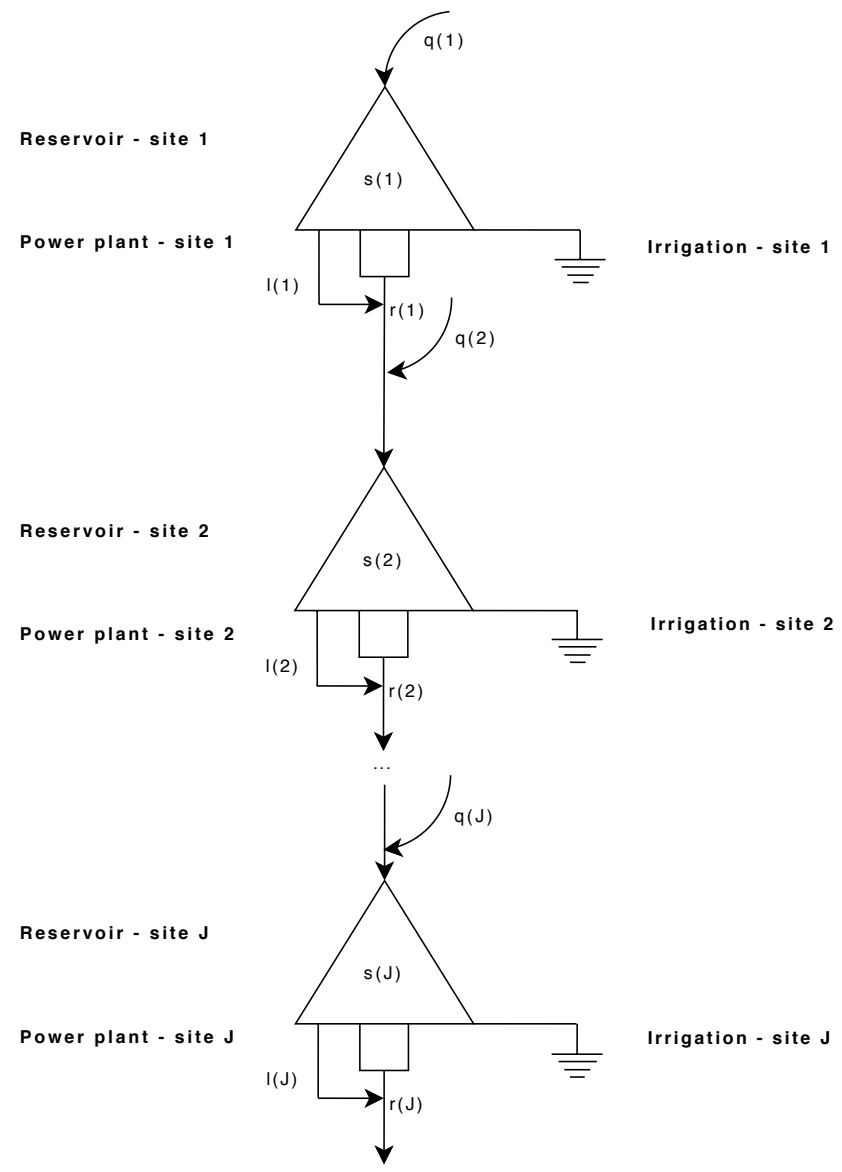

Fig. 1. Cascade of hydropower-irrigation reservoirs.

At-site value exceeds the at-source value by whatever costs are required to store, transport, and distribute water.

The total compensation $\alpha(j)$ of the $j$-th user should at least cover the forgone benefits, i.e. the value of the water transfers $\left(I_{t}-i_{t}\right)$ over the irrigation season.

$\alpha(j)=\sum_{t=t_{i}}^{t_{f}}\left[I_{t}(j)-i_{t}(j)\right] \lambda_{w, t}^{*}(j)$

Assuming that the conveyance costs are negligible (gravity irrigation) but that losses are significant, (16) can be written as a function of the at-source water value:

$\alpha(j)=\sum_{t=t_{i}}^{t_{f}}\left[I_{t}(j)-i_{t}(j)\right] \lambda_{w, t}(j) \epsilon(j)^{-1}$

The individual contributions of downstream power plants can then be derived from (17) using the chain rule: 


$$
\begin{aligned}
\alpha(j) & =\sum_{t=t_{i}}^{t_{f}}\left[I_{t}(j)-i_{t}(j)\right] \lambda_{w, t}(j) \epsilon(j)^{-1} \\
& =\sum_{t=t_{i}}^{t_{f}}\left[I_{t}(j)-i_{t}(j)\right]\left[\lambda_{w, t}(j)-\lambda_{w, t}(j+1)\right] \epsilon(j)^{-1} \\
& +\sum_{t=t_{i}}^{t_{f}}\left[I_{t}(j)-i_{t}(j)\right]\left[\lambda_{w, t}(j+1)-\lambda_{w, t}(j+2)\right] \epsilon(j)^{-1} \\
& \cdots \sum_{t=t_{i}}^{t_{f}}\left[I_{t}(j)-i_{t}(j)\right]\left[\lambda_{w, t}(J)-\lambda_{w, t}(J+1)\right] \epsilon(j)^{-1}
\end{aligned}
$$

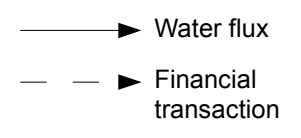

$$
\text { (n) }
$$$$
\text { 20 }
$$

Hydropower - site $j+k$

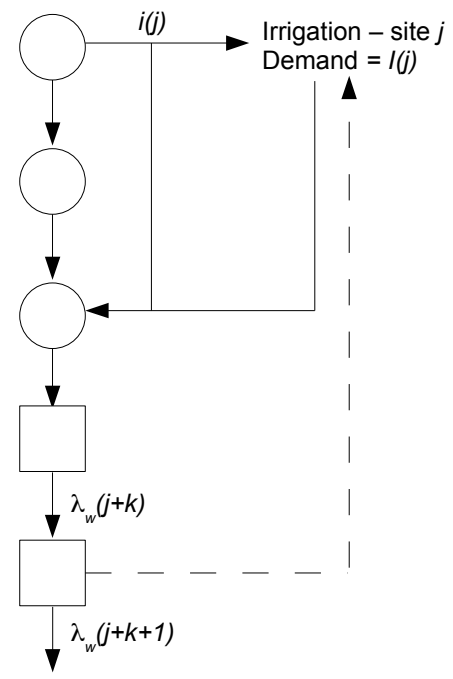

where $\lambda_{w, t}(J+1)=0$. For example, the financial transaction $\alpha(j+k, j)$ between the $(j+k)$-th hydropower plant and the $j$-th irrigation district (Fig. 2) is given by:

$$
\begin{aligned}
\alpha(j+k, j) & =\sum_{t=t_{i}}^{t_{f}}\left[I_{t}(j)-i_{t}(j)\right] \\
& \times\left[\lambda_{w, t}(j+k)-\lambda_{w, t}(j+k+1)\right] \epsilon(j)^{-1}
\end{aligned}
$$

where $\lambda_{w, t}(j+k)$ and $\lambda_{w, t}(j+k+1)$ are the marginal water values upstream and downstream of the $(j+k)$-th hydropower plant respectively. The difference between these two marginal water values reflects the productivity of that power station.

The compensation paid by the $(j+k)$-th hydropower plant to the upstream irrigation districts is

$$
\begin{aligned}
\alpha(j+k) & =\sum_{j=1}^{j+k} \alpha(j+k, j) \\
& =\left[\lambda_{w, t}(j+k)-\lambda_{w, t}(j+k+1)\right] \\
& \times \sum_{j=1}^{j+k}\left[I_{t}(j)-i_{t}(j)\right] \epsilon(j)^{-1}
\end{aligned}
$$

A comparison between the static and dynamic allocation approaches will be carried out next using the Euphrates system in Turkey and Syria as a case study. To achieve this, the two SDDP formulations described in Sect. 2 will be developed and implemented to determine the optimal allocation policies and the corresponding marginal water values. Then, from these results, the financial compensation between the hydropower and irrigation sectors will be assessed using the methodology explained above.

\subsection{The Euphrates river in Turkey and in Syria}

The Euphrates in Turkey and in Syria is essentially characterized by two projects: the GAP in Turkey and the Tabqa
Fig. 2. Financial compensation of an upstream irrigation district by a downstream power plant.

scheme in Syria. The GAP is one of the largest water resources development project in the world involving the construction of 22 dams, 19 hydroelectric power plants with an installed capacity of $7526 \mathrm{MW}$, and the irrigation of $1.7 \times 10^{6}$ ha in the Turkish part of the Euphrates and Tigris river basins. The GAP has always been considered as a strategic project for the Turkish authorities since the 1970s and the successive governments never gave it up despite the financial difficulties. The project is now behind schedule, with only $10 \%$ of the projected irrigation area in 1998, and the delays are not going to resorb as international funding agencies are not ready to finance international water projects without an agreement between co-riparians. Thus, Turkey is likely to bear alone the financial burden of the GAP unless it can agree on the question of sharing waters with Syria and Iraq (Kliot, 1994). The main Turkish dams built in the Euphrates are Keban, Karakaya, Ataturk, Birecik and Karkamis (Fig. 3). The main characteristics of these dams are listed in

In Syria, the Tabqa scheme which includes a hydropower plant $(880 \mathrm{MW})$ and several irrigation districts was also planned in the 70ies. In the first project made by the Soviets, 850000 ha were to be irrigated with the water of the Tabqa reservoir (lake Assad). This rather optimistic estimate has been downgraded several times and nowadays only 200000 ha are operational on the left and right banks of the Euphrates (Alia, 2007).

\section{Dynamic versus static management of the Euphrates river in Turkey and in Syria}

To illustrate the concept of dynamic management of a water resources system, we will use the Euphrates river basin Table 1. 
Table 1. Major dams in the Euphrates.

\begin{tabular}{lllll}
\hline Name & Id & Rated Capacity & Storage capacity & Irrigation \\
\hline Keban & $\mathrm{Kn}$ & $1240 \mathrm{MW}$ & $31.0 \mathrm{~km}^{3}$ & \\
Karakaya & $\mathrm{Ka}$ & $1800 \mathrm{MW}$ & $9.58 \mathrm{~km}^{3}$ & \\
Ataturk & $\mathrm{Ak}$ & $2400 \mathrm{MW}$ & $48.7 \mathrm{~km}^{3}$ & $\sqrt{ }$ \\
Birecik & $\mathrm{Bk}$ & $672 \mathrm{MW}$ & $1.22 \mathrm{~km}^{3}$ & $\sqrt{ }$ \\
Karkamis & $\mathrm{Ks}$ & $180 \mathrm{MW}$ & $0.157 \mathrm{~km}^{3}$ & \\
Tishreen & $\mathrm{Tn}$ & $630 \mathrm{MW}$ & $1.88 \mathrm{~km}^{3}$ & \\
Tabqa & $\mathrm{Ta}$ & $880 \mathrm{MW}$ & $14.16 \mathrm{~km}^{3}$ & $\sqrt{ }$ \\
\end{tabular}

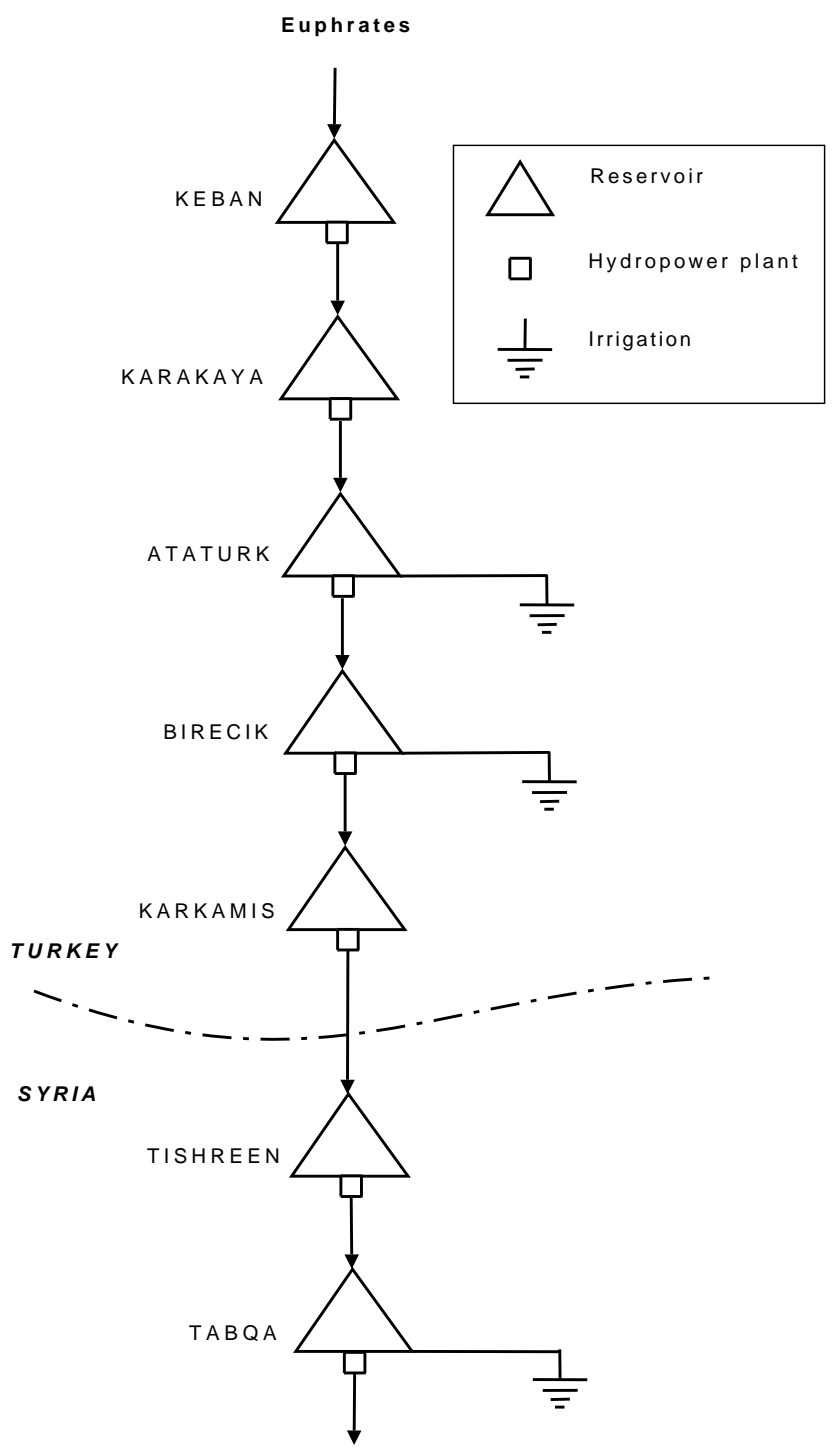

Fig. 3. Euphrates system in Turkey and Syria.

in Turkey and Syria. This system is used for illustrative purpose only as there is virtually no cooperation and coordination between riparians. We will therefore imagine that there is an institution responsible for (1) optimally allocating water between the different reservoirs and irrigation areas, (2) collecting water demands and water users' productivities, and (3) calculating the financial transactions between those who are better-off and those who are worse-off with the dynamic allocation scheme. Considering the large number of users, some level of aggregation is needed:

- Hydropower sector. Hydropower plants are individually considered but not turbines.

- Agricultural sector. All irrigation areas/districts supplied by the same reservoir are aggregated into a single irrigation district, and the corresponding irrigation water requirements (W) are assumed to be the official (planned) ones, i.e. $10000 \mathrm{~m}^{3} / \mathrm{ha} / \mathrm{yr}$ in Turkey (Kolars and Mitchell, 1994) and $12500 \mathrm{~m}^{3} / \mathrm{ha} / \mathrm{yr}$ in Syria (Alia, 2007). Irrigation efficiencies $(\epsilon)$ are assumed to be $45 \%$ in Turkey and $40 \%$ in Syria.

Table 2 lists the relative contribution of each month to the annual crop water requirements for a cropping pattern relying both on cereals (winter and spring wheat) and cotton. We can see that much of the irrigation water withdrawals $\left(i_{t}\right)$ will take place during the summer, from June to August.

With the above information, irrigation withdrawals, i.e. atsource irrigation water requirements, $\left(I_{t}\right)$ can be calculated from

$I_{t}=w_{t} \frac{W}{\epsilon}$

The analyzed system is depicted in Fig. 3 with 5 hydropower plants in Turkey and 2 in Syria. Two major irrigation districts are connected to the Ataturk and Birecik reservoirs in Turkey and one district is supplied by the Assad lake (Tabqa reservoir) in Syria. With such system, the vectors of initial storage volumes $s_{t}$ and accumulated water $y_{t}$ have 7 and 3 elements respectively.

Static allocation rules are first determined with the SDDP model (1)-(6): net benefits from hydropower generation are maximized for given, static, volumes of water diverted to the three irrigation districts. In other words, at each stage $t$, irrigation withdrawals $i_{t}$ are identical to at-source irrigation demands as long as there is enough water available in storage, i.e. $s_{t}+q_{t}-e_{t} \geq I_{t}$.

System performance associated with the static allocation is then estimated from simulation analysis using historical or synthetic flows. Here, 50 synthetic monthly inflow sequences are used to simulate the Euphrates system over a planning horizon of five years $(T=60)$, but simulation results are analyzed for year 3 only. This corresponds to a "steady state" condition which avoids the initial hydrological and storage conditions and the "end-effect" distortion due to the reservoirs depletion that happens as the end of the planning period approaches (Tilmant and Kelman, 2007). The 50 sequences are assumed representative of the stochastic inflow process and constitute a trade-off between representativeness and 
Table 2. Relative monthly irrigation water demands $-w_{t}$.

\begin{tabular}{llllllllllll}
\hline Jan & Feb & Mar & Apr & May & Jun & Jul & Aug & Sep & Oct & Nov & Dec \\
\hline- & - & - & - & 0.08 & 0.30 & 0.33 & 0.18 & 0.10 & 0.03 & - & - \\
\hline
\end{tabular}

computation time. A planning period of five years is required to deal with the multiyear storage capacity of some of the reservoirs listed in Table 1 . The more interesting simulation results for this study consists of the following $(50 \times 12)$ matrices: monthly volumes of water diverted for irrigation purposes from each reservoir, monthly releases through the turbines of each plant, the monthly spillage losses, monthly hydroelectric production of each plant, and monthly at-source marginal water values. These results are obtained after implementing the SDDP model (1)-(6) in simulation by exploiting the last (updated) set of piecewise linear benefit-togo functions $F_{t}$ available at each stage $t ; t \in[1, \cdots, T]$. Note that the term $i_{t}$ in the mass balance Eq. (2) correspond to the at-source irrigation water demands $I_{t}$ as explained above.

The same procedure is repeated with the SDDP model (8)(15) where allocation rules are chosen so as to maximize net benefits from both hydropower generation and crop irrigation using exactly the same hydrologic sequences as before with the static allocation. The only difference is that the decisions to allocate water in space and time are only driven by the productivity of the hydropower plants and irrigation districts. In other words, $i_{t}$ becomes a decision variable and it is no longer guaranteed that irrigation water demands will be met $\left(i_{t} \leq I_{t}\right)$, especially during dry periods when the marginal water value increases. As a matter of fact, during dry periods it may become more economically efficient to reallocate downstream a portion of the irrigation water demand $\left(I_{t}\right)$ as upstream farmers are competing with several downstream non-consumptive users.

The analysis of simulation results reveals that the expected net benefits with a dynamic allocation is larger than that obtained with a static management approach. The average difference between annual net benefits is 64 million US \$, which corresponds to a $6 \%$ increase with respect to the static approach. Figure 4 displays the cumulative distribution function of the differences between annual net benefits. We can see that $90 \%$ of the time the difference will be greater than 20 million US \$, with a maximum of 160 million US \$. We can also see that this difference is always positive, even during wet years when water is not scarce. The reason is to be found in that the development of the irrigation areas in Turkey was carried out independently of downstream riparians, therefore leading to overcommittment in the upstream part of the basin. If GAP were to be planned taking into account downstream water demands and productivities, Turkish irrigation areas and their water demands would probably be smaller. The difference between static and dynamic ben-

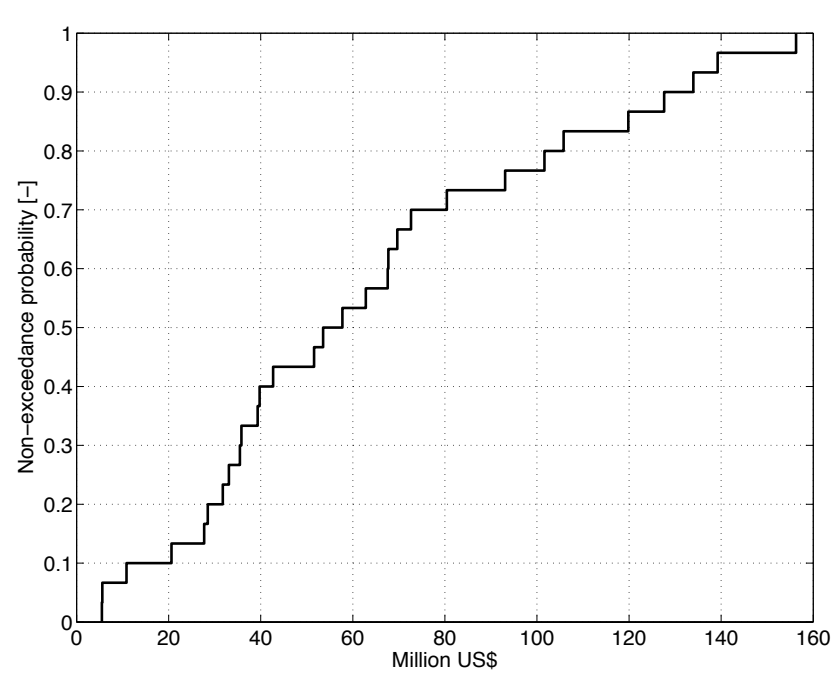

Fig. 4. Statistical distribution of the differences between dynamic and static annual benefits.

efits would also become negligible during wet years. In a sense, the extent of the differences between static and dynamic net benefits reveal the degree of cooperation and coordination when planning water resources development in a river basin.

A closer look at the hydropower and agricultural sectors is also revealing: on average, net benefits from the hydropower sector increase by 93.4 million US \$, whereas the agricultural sector looses as much as 29.5 million US \$. As expected the agricultural sector is worse-off with the dynamic allocation and a compensation mechanism must be established whereby the hydropower sector would financially compensate the agricultural sector for increasing the availability of water. However, since hydropower plants can be owned by different companies, the financial transactions must be developed between each power plant and each irrigation district according to the rules described in Sects. 2-3.

Figure 5 displays the average annual contribution of each power plant to the financial compensation of the three irrigation districts. The contribution of each power station is first calculated using Eq. (21) for each simulation sequence, and then averaged over the 50 sequences. The Ataturk hydropower plant only compensates the Ataturk irrigation district and the average payment would be around 9.9 million US \$. The downstream power plant, Birecik, would compensate the upstream irrigation districts, i.e. Ataturk (2.5 million US \$) and Birecik (1.8 million US \$). 


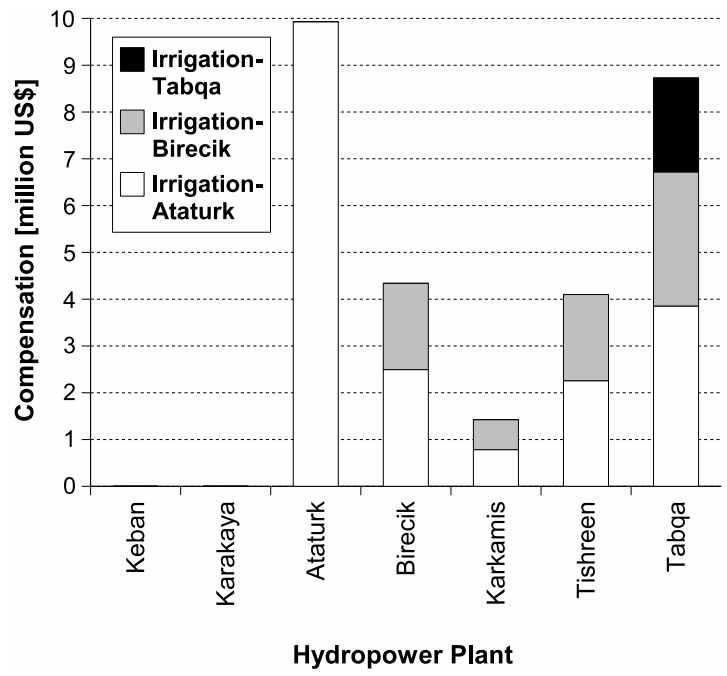

Fig. 5. Average contribution of the hydropower plants (million US \$).

Since more water is reallocated from the Ataturk irrigation scheme, the compensation is larger than that required for the Birecik irrigation scheme. The same pattern is observed for the Karkamis and Tishreen hydropower plants and we can see that their contribution is proportional to their productivity. Finally, Tabqa must compensate three irrigation districts: Tabqa, Birecik and Ataturk. Again, each irrigation district would be compensated in proportion to the volume of water being reallocated downstream. Table 3 lists the average individual contribution of the hydropower plants to the financial compensation of the three irrigation districts.

The extent to which the reallocation is taking place depends on the hydrologic status, which in turn is the outcome of a stochastic process. The financial compensation therefore varies according to the availability of water is the system, which is captured here with the 50 different simulation sequences. Figure 6 displays the statistical distributions of the annual compensations received by the Ataturk irrigation district from the downstream power plants (Ataturk, Birecik, Karkamis, Tishreen and Tabqa). We can see that the annual transaction varies between 3.2 and 37.6 million US \$, with an average of 19.3 million US \$. During dry years (with an exceedance probability of $90 \%$ ), the compensation will be at least equal to 29.5 million US \$, out of which 15.2, 5.6, 4.0, 3.5, 1.2 million US \$ come from Ataturk, Tabqa, Birecik, Tishreen and Karkamis hydropower plants respectively. Conversely, because little reallocation is taking place during wet years, the financial compensation is limited to less than 9 million US \$ $10 \%$ of the time. Figures 7 and 8 show the empirical statistical distributions of the annual compensation of Birecik and Tabqa irrigation demand sites. As we move downstream, fewer power plants participate in the compensation of the irrigation sites, making the reallocation less attractive.

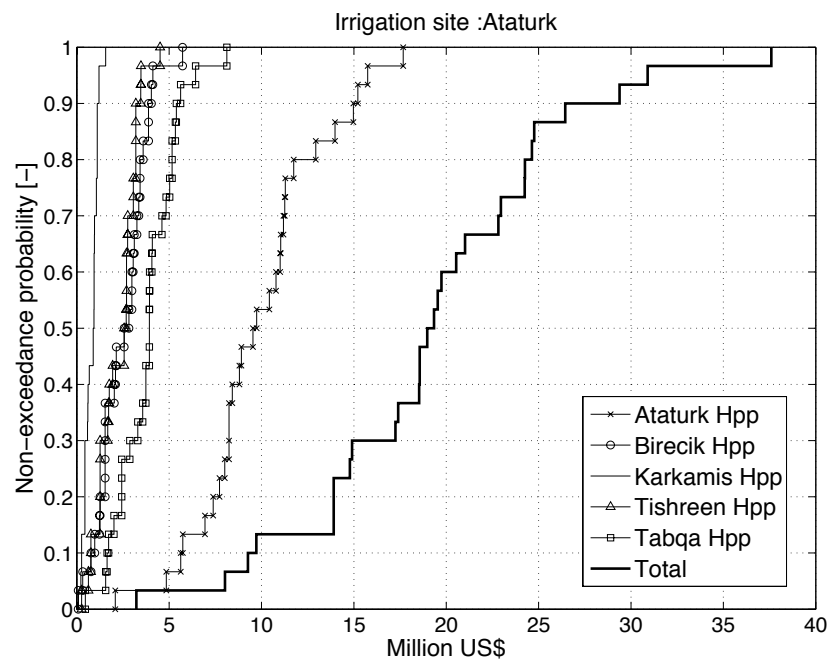

Fig. 6. Statistical distribution of the individual contribution of the hydropower plants - Ataturk Irrigation Site.

\section{Conclusions}

Dynamically managing water resources in a river basin consists in continuously adjusting allocation decisions based on the status of the system and thus on marginal water values. Under dry conditions, marginal water values will increase therefore signaling that priority be given to most productive uses. However, to make those efficient allocation decisions socially acceptable, a compensation mechanism must be developed in order to compensate the water users who have to forgo some (or all) of their individual benefits so that social benefits are maximized. This paper has presented a conceptual framework in which the water resources system is centrally managed by a river basin organization which determines optimal allocation decisions in space and time in such a way that the overall productivity is maximized. Then, the additional benefits obtained by this dynamic reallocation are redistributed to affected water users. In a system with large agricultural and energy sectors, upstream farmers are likely to be the first to see their entitlements reduced in case of droughts because downstream users, especially power companies, would form a coalition in order to attract as much water as possible downstream. This conceptual framework was tested on the cascade of hydropower-irrigation reservoirs in the Euphrates river basin. It was shown that a dynamic management increases the annual expected benefits by $6 \%$ and that the corresponding amount can be used to compensate the agricultural sector. We also presented a mechanism to assess the individual contribution of each hydropower plant to the financial compensation of upstream farmers. 
Table 3. Average contribution of the hydropower plants (million US \$).

\begin{tabular}{lllllll}
\hline & Hpp-Ataturk & Hpp-Birecik & Hpp-Karkamis & Hpp-Tishreen & Hpp-Tabqa & Total \\
\hline Irrigation-Ataturk & 9.9 & 2.5 & 0.8 & 2.3 & 3.8 & 19.3 \\
Irrigation-Birecik & 0.0 & 1.8 & 0.6 & 1.8 & 2.9 & 7.2 \\
Irrigation-Tabqa & 0.0 & 0.0 & 0.0 & 0.0 & 2.0 & 2.0 \\
\hline Total & 9.9 & 4.3 & 1.4 & 4.1 & 8.7 & 28.5 \\
\hline
\end{tabular}

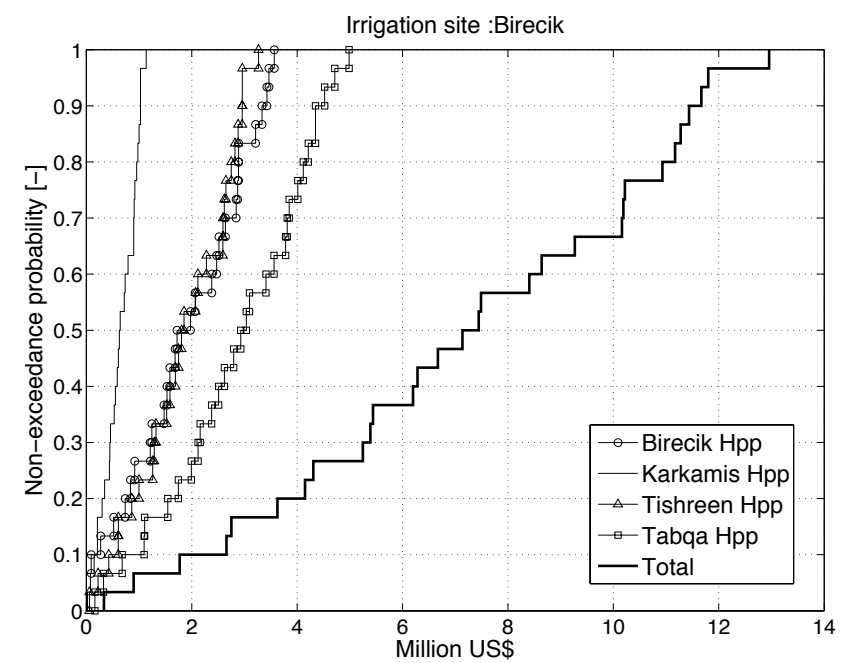

Fig. 7. Statistical distribution of the individual contribution of the hydropower plants - Birecik Irrigation Site.

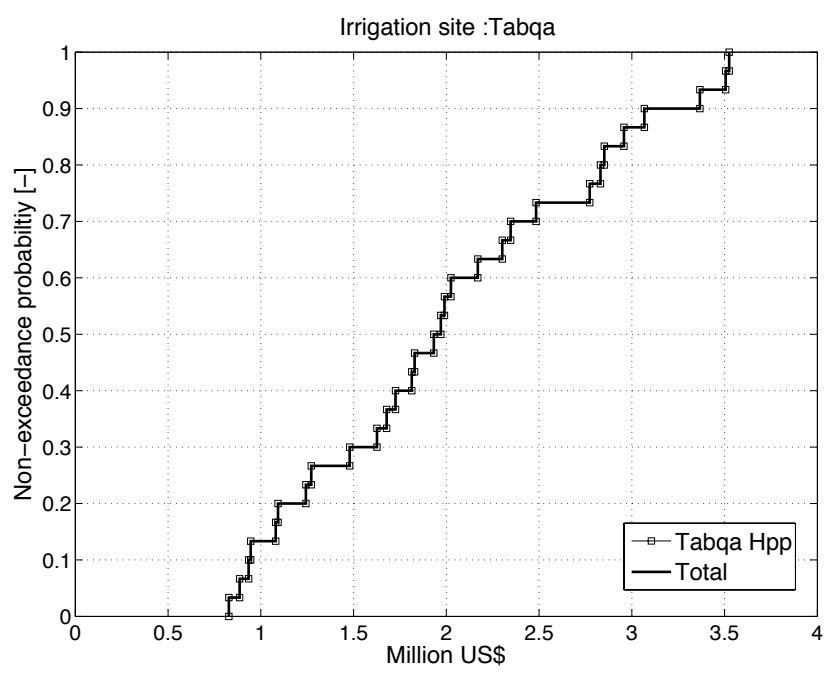

Fig. 8. Statistical distribution of the individual contribution of the hydropower plants - Tabqa Irrigation Site.
Edited by: A. Montanari

\section{References}

Alia, A.: Bi-objective dynamic programming for trading-off hydropower and irrigation - Tabqa dam, Master's thesis, UNESCOIHE, Delft, The Netherlands, 2007.

Barosso, L., Fampa, M., Kelman, R., Pereira, M., and Lino, P.: Market power issues in bid-based hydrothermal dispatch, Ann. Oper. Res., 117, 247-270, 2002.

Beaumont, P.: Agricultural and environmental changes in the upper Euphrates catchment of Turkey and Syria and their political and economical implications, Appl. Geogr., 16, 137-157, 1996.

Booker, J. and Young, R.: Modeling intrastate and interstate markets for Colorado river water resources, J. Environ. Econ. Manag., 26, 66-87, 1994.

Braden, J. and Johnston, D.: Downstream economic benefits from storm-water management, J. Water Res. Pl.-ASCE, 130, 498505,2004

Cai, X., McKinney, D., and Lasdon, L.: Integrated hydrologicagronomic-economic model for river basin management, J. Water Res. Pl.-ASCE, 129, 4-16, 2003.

Davis, M.: Integrated water resources management and water sharing, J. Water Res. Pl.-ASCE, 133, 427-445, 2007.

Dinar, A., Rosegrant, M., and Meinzen-Dick, R.: Water allocation mechanisms: Principles and examples, World Bank Technical Paper 1779, Washington, USA, 1997.

Fisher, F., Huber-Lee, A., and Amir, I.: Liquid assets: an economic approach for water management and conflict resolution in the Middle east and beyond, Resources of the Future, Washington, USA, 2005.

Fleten, S.-E.: Portfolio management emphasizing electricity market applications - A stochastic programming approach, NTNU, Trondheim, Norway, 2000.

Gibbons, D.: The Economic Value of Water, Resources for the Future, Washington D.C., USA, 1986.

Johnston, D., Braden, J., and Price, T.: Downstream economic benefits of conservation development, J. Water Res. Pl.-ASCE, 132, 35-43, 2006.

Kliot, N.: Water Resources and Conflict in the Middle East, Routledge, London, 1994.

Kolars, J. and Mitchell, W.: The Euphrates river and the Southeast Anatolia Project, Southern Illinois University Press, Carbondale, USA, 1994.

Labadie, J. W.: Optimal operation of multireservoir systems: Stateof-the-art review, J. Water Res. Pl.-ASCE, 130, 93-111, 2004.

Molle, F., Wester, P., Hirsch, P., Jensena, J., Murray-Rust, H., Paranjpye, V., Pollard, S., and van der Zaag, P.: Water for Food, 
Water for Life: A Comprehensive Assessment of Water Management in Agriculture, Earthscan and Colombo, International Water Management Institute, London, 585-624, 2007.

Nkomo, S. and van der Zaag, P.: Equitable water allocation in a heavily committed international catchment area: the case of the Komati catchment, Phys. Chem. Earth, 29, 1309-1317, 2004.

Oven-Thompson, K., ALercon, L., and Mark, D.: Agricultural vs. hydropower tradeoffs in the operation of the High Aswan dam, Water Resour. Res., 18, 1605-1613, 1982.

Pereira, M.: Optimal stochastic operations of large hydroelectric systems, Electrical Power and Energy Systems, 11, 161-169, 1989.

ReVelle, C.: Optimizing Reservoir Resources - Including an New Model for Reservoir Reliability, John Wiley, NY, USA, 1999.

Rosegrant, M., Ringler, C., McKinney, D., Cai, X., Keller, A., and Donoso, G.: Integrated economic-hydrologic water modeling at the basin scale: The maipo riverbasin, Agr. Econ., 24, 33-46, 2000.

Sadoff, C. and Grey, D.: Beyond the river: the benefits of cooperation on international rivers, Water Policy, 4, 389-403, 2002.

Scott, T. and Read, E.: Modelling hydro reservoir operation in a deregulated electricity market, International Transactions in Operational Research, 3, 243-253, 1996.

Tejada-Guibert, A., Johnson, S., and Stedinger, J.: Comparison of two approaches for implementing multireservoir operating policies derived using stochastic dynamic programming, Water Resour. Res., 29, 3969-3980, 1993.
Tilmant, A. and Kelman, R.: A stochastic approach to analyze trade-offs and risks associated with large-scale water resources systems, Water Resour. Res., 43, W06425, doi:10.1029/2006WR005094, 2007.

TTilmant, A., van der Zaag, P., and Fortemps, P.: Modeling and analysis of collective management of water resources, Hydrol. Earth Syst. Sci., 11, 711-720, 2007, http://www.hydrol-earth-syst-sci.net/11/711/2007/.

Tilmant, A., Pinte, D., and Goor, Q.: Assessing marginal water values in multipurpose multireservoir systems via stochastic programming, Water Resour. Res., 44, W12431, doi:10.1029/2008WR007024, 2008.

Vedula, S. and Kumar, D.: An integrated model for optimal reservoir operation for irrigation of multiple crops, Water Resour. Res., 28, 1101-1108, 1996.

Ward, F. and Michelsen, A.: The economic value of water in agriculture: concepts and policy applications, Water Policy, 4, 423446, 2002.

Ward, F., Booker, J., and Michelsen, A.: Integrated economic, hydrologic, and institutional analysis of policy responses to mitigate drought impacts in rio grande, J. Water Res. Pl.-ASCE, 132, 488-501, 2006.

Yeh, W.: Reservoir management and operations models: a state-ofthe-art review, Water Resour. Res., 21, 1797-1818, 1985.

Young, R.: Determining the Economic Value of Water - Concepts and Methods, Resources of the Future, Washington, USA, 2005. 